\title{
Integrated Management of Major Coconut Pests Using Pheromone Lures
}

\author{
K. R. M. Bhanu ${ }^{1}$, K. P. Jayanth, M. Thomas Mathew ${ }^{2}$ and M. S. Prabhakara
}

\begin{abstract}
Red palm weevil Rhynchophorus ferrugineus Olivier (Coleoptera: Curculionidae; Rhinoceros beetle Oryctes rhinoceros Linn. (Coleoptera: Scarabidae) and Black headed caterpillar Opisina arenosella Walker (Lepidoptera: Oecophoridae) are the three among major insect pests of coconut in India. Grubs of Red palm weevil (RPW) enter and complete their life cycle within the stem, killing the tree, adults of Rhinoceros beetle (RB) feed on the growing point of the tree and cause yield loss and the larvae of black headed caterpillar scrape and feed on the green part of the coconut leaflets leading to burnt symptoms of the fronds, death of young trees and yield loss. Aggregation pheromones of RPW and RB are used for monitoring and mass trapping of RPW and RB to manage the pest under economic threshold level. During 2006-07 large scale field trials for RPW and RB were carried out in four different states in India by PCI under a partially funded Coconut Development Board (CDB) project using indigenously synthesized pheromone lures. It was demonstrated that the pheromone lures predominantly attracted virgin and gravid females of RPW and RB. Female sex pheromone of black headed caterpillar Opisina arenosella was also identified and developed in India by PCI, under a project partially funded by $\mathrm{CDB}$; dispensers, dosage and traps were standardized under field conditions and further trials were also conducted in India. It was also established that pheromone lures can be used as a monitoring and a surveillance tool for understanding the pest status before the release parasitoids and natural enemies.
\end{abstract}

Keywords: aggregation pheromones, black headed caterpillar, red palm weevil, rhinoceros beetle, sex pheromones

\footnotetext{
${ }^{1}$ Bio-Control Research Laboratories, A division of Pest Control (India) Pvt Ltd., 36/2, Sriramanahalli, Nr. Rajankunte, Dodballapur Road, Bangalore-561 203, India. Email: bhanu.krm@pcil.in

${ }^{2}$ Coconut Development Board, Kera Bhavan, Kochi 682 011, Kerala, India.
} 


\section{Introduction}

Coconut is one of the most important palms grown across tropical and subtropical countries and has several domestic, commercial and industrial uses. Red palm weevil (RPW), Rhinoceros beetle (RB) and Black headed caterpillar (BHC) are among the most serious insect pests causing yield losses and death of trees. Females of $R$. ferrugineus lays eggs on wounded parts of coconut tree mostly on the stem and all the stages of its life cycle are completed within the coconut stem. Continuous feeding by the RPW grubs for more than one generation causes breaking of the stem and toppling of affected palm. Due to the concealed nature of its feeding, one cannot easily detect RPW infestation in the early stages and farmers become aware of the problem only when the tree is about to die. Although palms of all ages are prone to the attack of RPW, young palms up to the age of 20 years are preferred. In case of $O$. rhinoceros, its immature stages will be completed in manure pits or decaying organic matter in and around the field and only adults attack coconut palms. RB adults feed and burrow into the growing points of palms causing damage to the fronds, spathes and crown, which in turn results in yield loss and even death of young palms. The wounds caused by RB can be ideal breeding sites for RPW. During our survey in 2006-07, in four states in India, it was observed that out of 355 coconut farmers having different acreages of coconut plantations, an average of $19.03 \%$ trees died during the previous five years due to RPW \& RB attack (Jayanth et al, 2010). Chemical methods, including spraying of the palms with high pressure sprayers, stem injection of infested palms and spot application of fumigant tablets were only moderately successful in containing the infestation and dispersal of the pest (Abraham et al., 2002; Vidhyasagar et al., 2000; Kalidas., 2004).

Black headed caterpillar which has discrete generation cycles in India, lays about 130 eggs per female nearer to the damaged leaflets of coconut fronds. The caterpillars feed on to the green part of the coconut leaflets causing burnt symptoms of the fronds from bottom and moves towards the upper fronds.
Biological control measures like release of natural enemies are not always successful because of the difficulty in identifying the pest status, prolonged larval period, nature of damage, height of the trees etc,. Chemical methods like stem injections and root feeding methods are moderately successful.

\section{Disadvantages of existing management methods}

Most of the mechanical methods to manage RPW \& RB are laborious. Chemical insecticides are not able to reach the target pest and fail to give desired results. Further, chemical insecticides are hazardous and difficult to apply. Though many natural enemies available, particularly for BHC, and attempts are being made to mass produce parasites, farmers are not able to get the required quantity in time. Under these conditions, pheromones can play a crucial role by providing a reliable, cost-effective and simple tool for surveillance, monitoring and mass trapping of the pest.

\section{Pheromones}

Pheromones are released by males or females of a species to attract or communicate to other males or females of the same species. If the pheromone is released by a male or female and elicits response in either male or female it is called aggregation pheromone. Whereas, pheromone released by male or female which elicits response in opposite sex is called sex pheromones. Sex pheromones are mainly used for calling their opposite gender for mating. Aggregation pheromones may be used either for mating, oviposition, foraging, etc.

The male produced aggregation pheromone of $R$. ferrugineus (4-methyl-5nonanol) was first identified by Hallet et al. (1993) while Ochlschlager et al. (1993) designed a pheromone based trapping system. The aggregation pheromone of the $O$. rhinoceros, viz., ethyl 4- methyloctanoate, was reported for the first time by Gries et al (1994) and Norman et al (1999) recommended its use for mass trapping the pest attacking oil palm in Malaysia. Female sex pheromone (Z,Z,Z)-3,6,9tricosatriene was identified by NRI, UK during 
1990s; (Cork et al., 1998) and synthesized and field tested in India during 2006-08. Pheromone trapping is adopted widely for management of RPW in date palms in Saudi Arabia (Abraham et al., 2000). Capability of RB pheromone in attracting RB adults to baited traps in oil palm and coconut plantations in India has also been reported (Kalidas, 2004; Rajalakshmi et al., 2007). Nevertheless, the efficacy of pheromone traps in reducing the population densities of RPW and RB in India was not established. Area wide adoption of pheromone technology for management of coconut pests in India is also hampered by the high cost of imported pheromone lures.

The presence of female sex pheromones were discovered by Srinivasa Murthy et al., (1995) and Natural Resources Institute, UK identified pheromone components from female moth extracts and some field studies carried out in Sri Lanka. During 2006 - 08, Pest Control (India) Pvt. Ltd., once again tried to identify the female sex pheromones with help of NRI, UK and carried out the field trials with the synthetic pheromones under a project partially funded by Coconut Development Board.

\section{Materials and Methods}

To demonstrate the efficacy of pheromone technology, area wide mass trapping was carried out in 100 acres each in Kerala, Karnataka, Tamil Nadu and Andhra Pradesh states in India with a total of 400 acres over four different states for both RPW and RB during 2006-07. A total of 800 pheromone traps were used for the study @ 1trap / acre for each pest RPW and RB. Trap catches data was collected once in a week from all the traps. Pheromone lure of RPW consists of $800 \mathrm{mg}$ of pheromone blend with a combination of 4-methyl-5-nonanol and 4methyl-5-nonanone in 9:1 ratio in a pvc blister formulation. Pheromone lure for RB consists of $300 \mathrm{mg}$ of ethyl-4-methyl octanoate impregnated in a pvc vial dispenser. All the three components were indigenously synthesized at Bio-Control Research Laboratory (BCRL), Bangalore. Bucket traps tied at a height of 4-5 feet height from the ground level were used to trap the weevils and beetles. Few pieces of coconut shavings in two liters water were used as food bait in bucket traps with $1 / 2$ tea spoon detergent powder as wetting agent to kill the trapped beetles and the traps were serviced once in every 15 days period. Observation on number of beetles caught in each trap was carried out on weekly basis. A control field consisting of ten acres was maintained in each state, away from the trial plot. Ten traps were set up in each field, one month before and after the project period. The data for four weeks was collected before and after the trial period on weekly basis. Specimens of beetles and weevils were brought to BCRL for dissection to study reproductive status.

The female sex pheromone (Z,Z,Z)-3,6,9tricosatriene was indigenously synthesized and pheromone lures were also prepared at BCRL, Bangalore, India. Wingwane (sandwich type) trap was used for field studies. The traps were tied to lower fronds with 2-3 inch distance from the frond. Observations on trap catches were taken on weekly basis.

\section{Results and Discussion}

\section{Mass trapping of Red palm weevil and Rhinoceros Beetle using aggregation pheromones:}

During the course of area wide mass trapping, a total of $27,915 \mathrm{RPW}$ adults were caught in aggregation pheromone traps installed in 400 acre project demonstration areas in the four states, over the 10 month study period from May 2006 to February 2007. In the case of R.B a total of 12,773 adults were caught in aggregation pheromone traps installed in 400 acre project demonstration areas in the four states, over the 10 month study period from May 2006 to February 2007. It was observed that the peak emergence period in case of both RPW and RB is from September to November and then declines. The trend in the following Fig $1 \& 2$ shows that the initial catches were high when compared to the last month catches. Similarly RPW month wise trap catches was depicted in Fig 3.

It is clear from all the above figures that the catches were high during the beginning of the study period and reduced towards the end of 
the study period. Emergence was high between September to November months. There was a decreasing trend from the beginning till the end of the trial period in RPW and RB catches.

Mean percentage reduction of trap catches over the first month was calculated from the ten months data and tabulated in the Table 1 for RB and Table 2 for RPW. It was observed that the mean reduction varied from $9.49 \%$ to $92.70 \%$ among all the four states to a mean of $58.76 \%$ reduction. In case of RPW, the mean reduction was observed to vary from $2.45 \%$ to $35.95 \%$ among all the four states to a mean of $18.73 \%$ overall reduction. The percentage reduction of RPW catches over first month to last month in the trial plot was compared with the control plot data (Fig. 4). It was observed that there was a reduction of $18.73 \%$ catches in treatment plot; whereas in control plot there was an increase of $4.25 \%$ weevil catches. Similarly, there was a decrease of Rhinoceros beetles $58.76 \%$ over first month catches in case of trial plot where as in control plot, it was found that there was an increase of $43.51 \%$ catches which shows that there was population build up in control or untreated plots.

RPW adults caught in pheromone traps, during the study period, was found to be female biased, with 17,836 females as against 10,079 males, which in turn was highly significant $(\mathrm{P}=0.01)$ as determined by student ' $\mathrm{t}$ ' test (Table 3 ). The sex ratio was found to range from 1: 1.59 to 1: 1.94 (male: female) during the different months, with a mean of 1: 1.77 (male: female) for the entire study period. The proportion of females was found to be highly significant in each of the four states as well, with the highest values being obtained in Kerala (1:1.99) followed by Karnataka (1:1.96), Tamil Nadu (1:1.66) and Andhra Pradesh (1:1.41).

As in the case of RPW, adult catches in RB pheromone traps was also found to be female biased for all the states together, as also for each of the four states. Thus 8,629 females were caught from the project demonstration areas in the four states as against 4,144 males, which in turn was highly significant $(\mathrm{P}=0.01)$, as determined by student ' $t$ ' test (Table 3 ).
Further, the reproductive status of the females was identified by dissecting the beetles which were caught in the bucket traps. These beetles were graded for convenience as shown in the following table as virgin, gravid, laying and spent females. About $54.13 \%$ virgin females, and $33.87 \%$ gravid females and $11.5 \%$ females laying eggs were found in RPW pheromone traps. Similarly $50.88 \%$ virgin females, and $27.50 \%$ gravid females and $16.13 \%$ females laying eggs were found in RB pheromone traps. This shows that there is a possibility of managing these pests by using pheromone traps as stand alone method.

\section{Female sex pheromones of Black headed caterpillar:}

The trial data shows that $100 \mu \mathrm{g}$ of pheromone in pvc vial when used with wing wane trap with one sided glue tied to coconut palm frond is attracting and trapping BHC adults efficiently.

The trap catches in Fig. 5 represents the peak emergence period of BHC in the field. Laboratory observations carried out using pupae collected from the study fields also established that pheromone trap catches coincided with the emergence pattern of adults, indicating the potential of using this technology as a stand alone tool in managing this pest by mass trapping after standardizing trap design, height of installation and dosages per hectare. The studies carried out from $2006-07$ also demonstrated the potential of using sex pheromone traps as an effective tool for surveillance and monitoring of $O$. arenosella. Data on emergence pattern, obtained by installation of pheromone traps in endemic areas, can be used to develop a strategy for determining optimum time for release of larval parasitoids for effective suppression of the pest, to prevent their further dispersal. 
Figure 1. Month wise mean number of Rhinoceros beetle catches in four different states

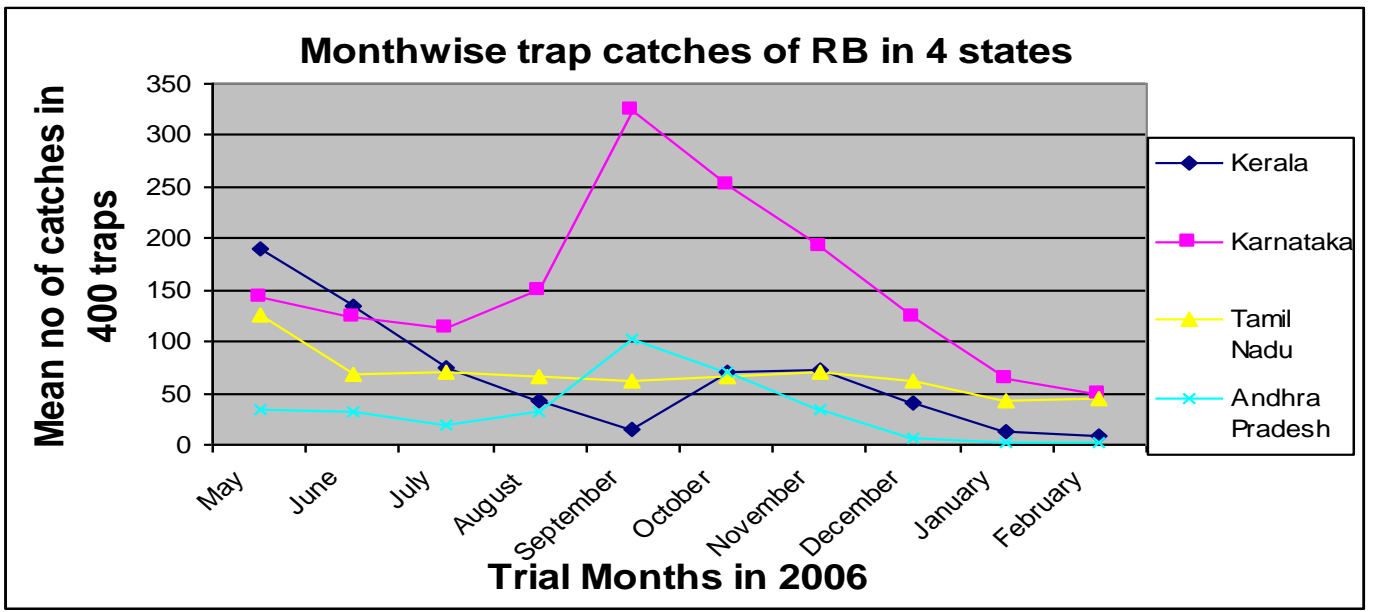

Figure 2. Month wise mean number of Rhinoceros beetle catches in 400 acre in four different states

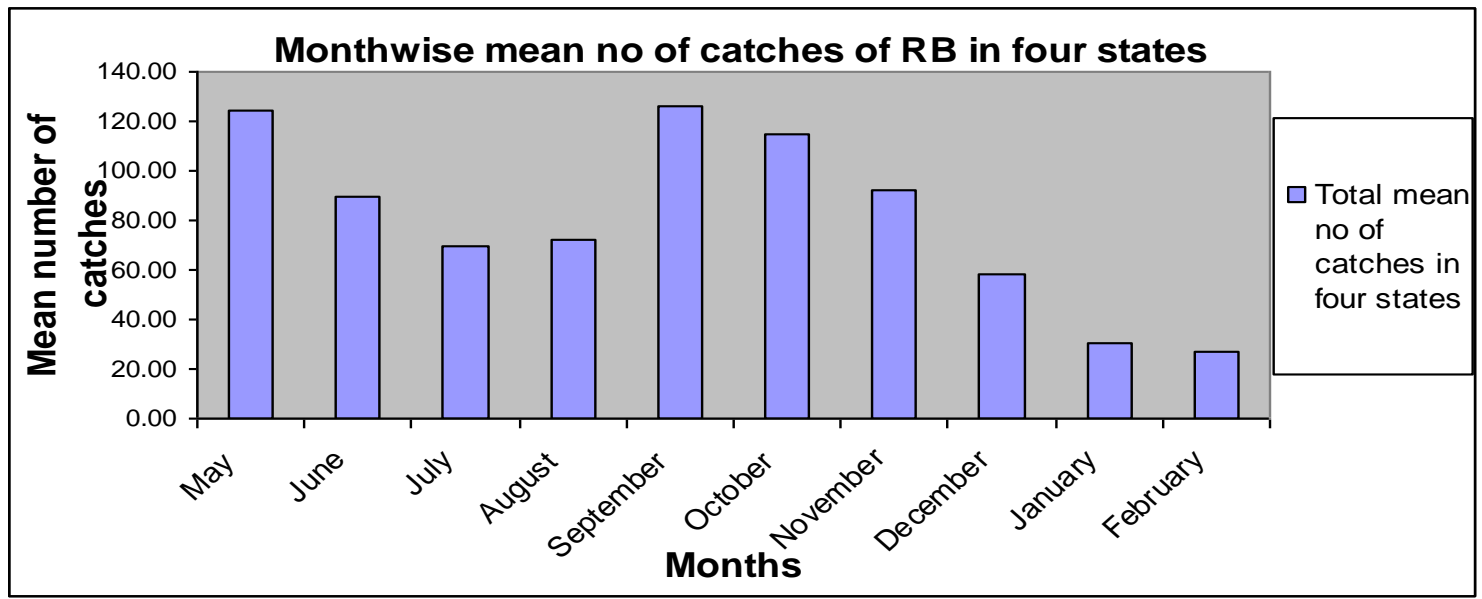

Figure 3. Month wise mean number of Red palm weevil catches of in four different states

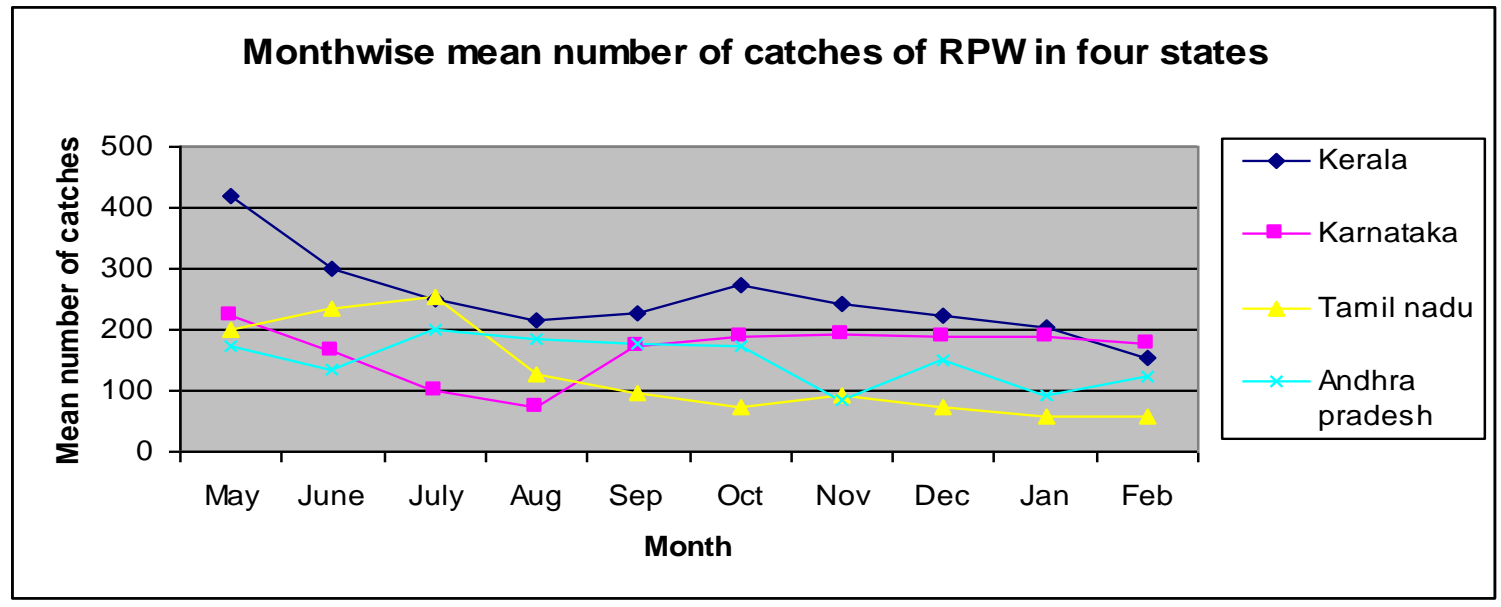


Figure 4. Pheromone Trap catches of RPW and RB

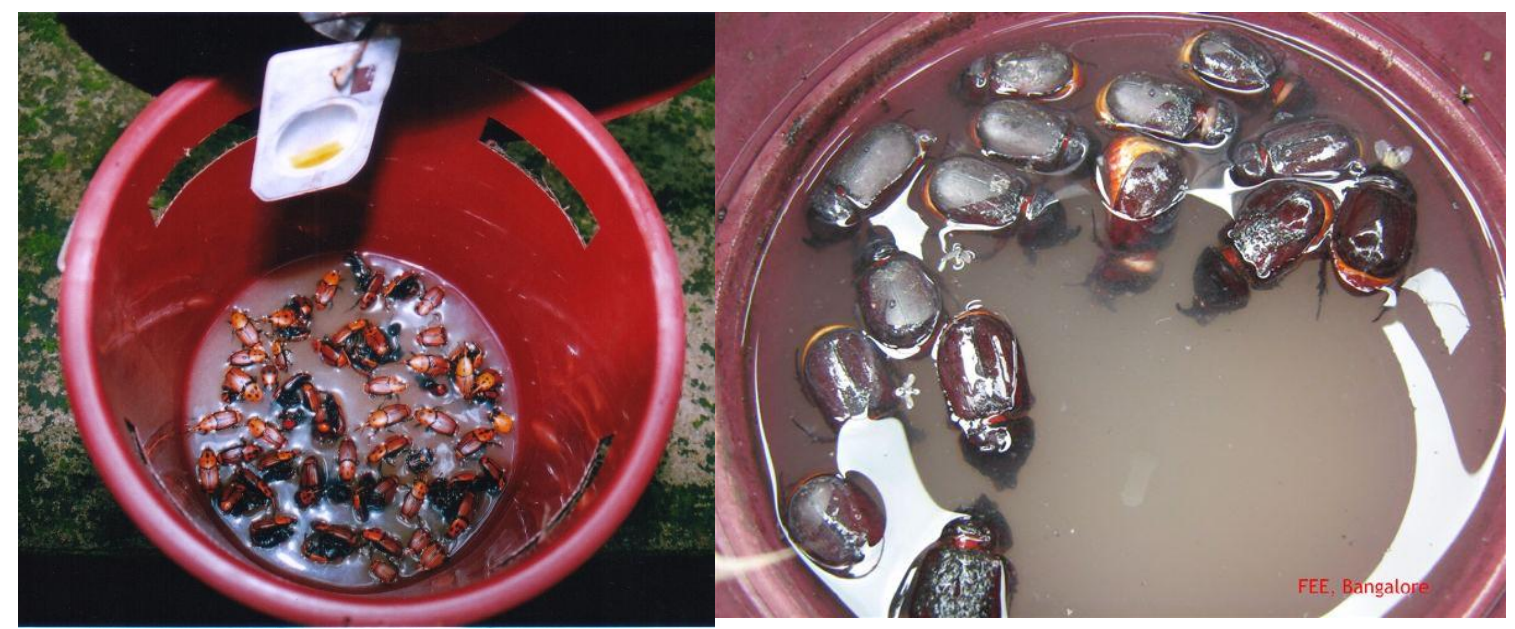

Table 1. Mean number of Rhinoceros Beetles caught per trap per month with mean per cent reduction over $1^{\text {st }}$ month in different states

\begin{tabular}{|c|l|c|c|}
\hline S. No. & Location & $\begin{array}{c}\text { Mean no of beetle } \\
\text { caught / trap/ } \\
\text { month }\end{array}$ & $\begin{array}{c}\text { Mean \% reduction in } \\
\text { catches over 1 } \text { 1 }^{\text {month }}\end{array}$ \\
\hline 1 & Kerala & 1.84 & 75.39 \\
2 & Karnataka & 5.44 & 57.47 \\
3 & Tamil Nadu & 2.24 & 9.49 \\
4 & Andhra Pradesh & 1.13 & 92.70 \\
\hline & Mean \pm SD & $2.66 \pm 1.91$ & $58.76 \pm 35.86$ \\
\hline
\end{tabular}

Table 2. Mean number of Red palm weevils caught per trap per month with mean per cent reduction over $1^{\text {st }}$ month in different states

\begin{tabular}{|c|l|c|c|}
\hline S. No. & \multicolumn{1}{|c|}{ Location } & $\begin{array}{c}\text { Mean no of weevil } \\
\text { caught / trap/ month }\end{array}$ & $\begin{array}{c}\text { Mean \% reduction in } \\
\text { catches over 1 }\end{array}$ month \\
\hline 1 & Kerala & 7.81 & 35.95 \\
2 & Karnataka & 5.94 & 2.45 \\
3 & Tamil Nadu & 4.16 & 25.94 \\
4 & Andhra Pradesh & 5.36 & 10.56 \\
\hline & Mean \pm SD & $5.82 \pm 1.52$ & $18.73 \pm 15.06$ \\
\hline
\end{tabular}


Table 3. Sex ratio of RPW and RB trapped in pheromone traps across four states

\begin{tabular}{|l|c|c|c|c|}
\hline \multirow{2}{*}{ Site } & \multicolumn{2}{|c|}{ RPW } & \multicolumn{2}{c|}{ RB } \\
\cline { 2 - 5 } & Sex ratio & t $\alpha$ (5\%), N=100 & Sex ratio & t $\alpha(5 \%), \mathbf{N}=100$ \\
\hline Kerala & $1: 1.99$ & $26.15^{* *}$ & $1: 2.72$ & $18.382^{* *}$ \\
Karnataka & $1: 1.96$ & $29.517^{* *}$ & $1: 1.81$ & $22.96^{* *}$ \\
Tamil Nadu & $1: 1.66$ & $16.151^{* *}$ & $1: 1.91$ & $13.84^{* *}$ \\
Andhra Pradesh & $1: 1.41$ & $11.636^{* *}$ & $1: 3.69$ & $16.34^{* *}$ \\
\hline
\end{tabular}

Table 4. Reproductive status of RPW \& RB

\begin{tabular}{|c|c|c|c|}
\hline S. No. & Grades & $\% \mathbf{R B}$ & \% RPW \\
\hline 1 & $\begin{array}{l}\text { Grade-1 } \\
\text { (Virgin) }\end{array}$ & $54.13 \%$ & $50.88 \%$ \\
\hline 2 & $\begin{array}{l}\text { Grade-2 } \\
\text { (Gravid) }\end{array}$ & $33.87 \%$ & $27.50 \%$ \\
\hline 3 & $\begin{array}{l}\text { Grade-3 } \\
\text { (Laying) }\end{array}$ & $11.5 \%$ & $16.13 \%$ \\
\hline 4 & $\begin{array}{l}\text { Grade-4 } \\
\text { (Spent) }\end{array}$ & $0.5 \%$ & $5.50 \%$ \\
\hline
\end{tabular}


Figure 5. Relation between emergence of males in the laboratory and trap catches in the field

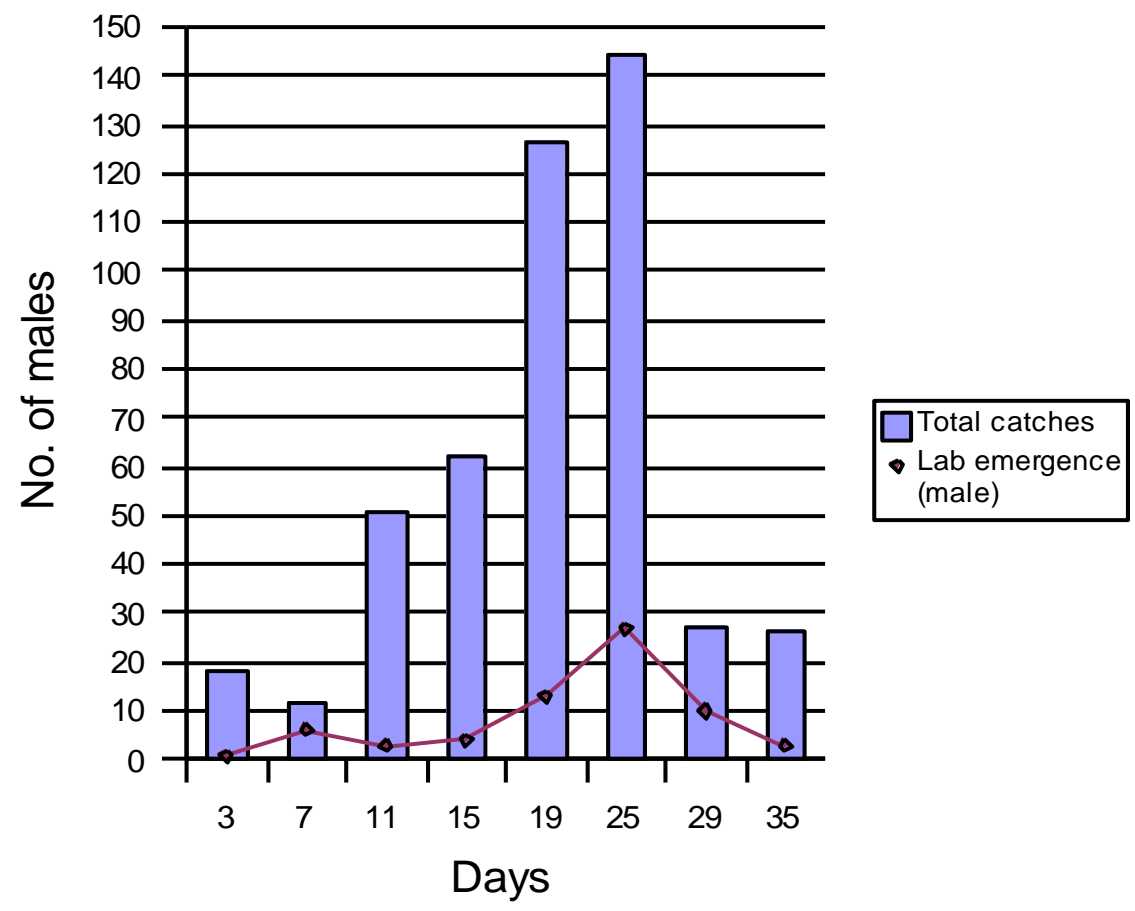

Figure 6. Coconut trees infested with Black headed caterpilar and moths trapped in pheromone Trap

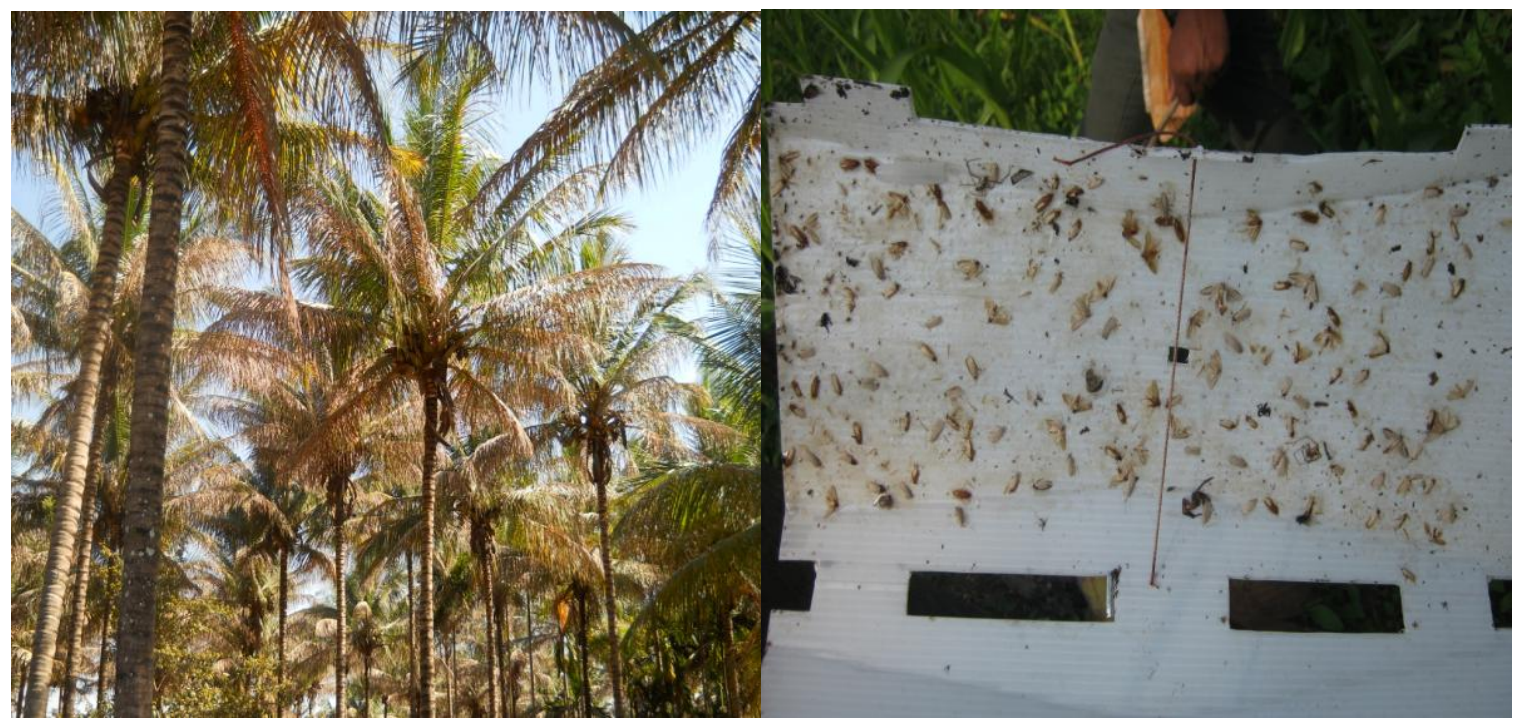




\section{Conclusion}

The results of large scale trials with RPW and $\mathrm{RB}$ aggregation pheromone traps indicated that the trap catches are female biased and among females, virgin and gravid stages were found to be the maximum. Further, this study indicated that per cent reduction is very high when compared with control plots. Pheromone traps of BHC can be used as a surveillance and monitoring tool for the pest which alerts for timely action of releasing parasitoids. Further studies have been initiated for establishing the other management methods of mass trapping and integration of pheromones with parasitoids under farmer's field condition.

Pheromone traps are safer, user friendly, environment friendly and target oriented pest management methods. When integrated with other successful regular practices of cutting and burning of infested fronds and mass-release of parasitoids (Murali Mohan et al 2007) by monitoring with pheromone lures will be a successful strategy for the management of this noxious pest. Good sanitation and irrigation in case of RPW and RB and bucket traps baited with RPW and RB pheromone lures can be used for early detection of infestation, trapping floating populations of adults and also used for mass trapping as a key component of integrated pest management.

\section{Acknowledgement}

The authors are grateful to Chairman, Coconut Development Board for partial funding of the two projects and the kind support. The authors are also indebted to Mr. Anil S. Rao, Chairman and Managing Director, Pest Control (India) Pvt Ltd for his encouragement.

\section{References}

Abraham, V. A., Faleiro, J. R., Al Shuaibi M. A., and Prem Kumar T. 2000. A strategy to manage red palm weevil Rhynchophorus ferrugineus Oliv. on date palm Phoenix dactylifera L. - Its successful implementation in Al-Hassa, Kingdom of Saudi Arabia. Pestology, 24: 23-30.
Abraham, V. A., Faleiro, J. R., Nair, C. P. R. and Nair, S. S. 2002. Present management technologies for red palm weevil, Rhynchophorus ferrugineus Olivier (Coleoptera: Curculionidae) in palms and future thrusts. Pest Management in Horticultural Ecosystems, 8: 69-82.

Cork, A and Hall, D. 1998. Journal of AsiaPacific Entomology, 1: 35-49

Gries, G., Gries, R., Perez, A. L., Oehlschlager, A. C., Gonzales, L. M., Pierce, H. D., Jr:, Zebeyou, M. and Kouame, B. 1994. Aggregation pheromone of the African Rhinoceros Beetle, Oryctes rhinoceros (Olivier) (Coleoptera: Scarabidae). Z. Naturforsch 49: 363-366.

Hallet, R.H., Gries, R. H., Borden, J. H., Czyzewska, E., Ochlschlager, A. C., Pierce Jr. H. S., Angerili, N. P. D. and Rauf, A. 1993. Aggregation pheromone of two Asian palm weevils Rhynchophorus ferrugineus and $R$. culneratus. Naturwissenschfien 80: 328-331.

Jayanth K.P., Thomas Mathew and Bhanu K.R.M. 2010. Demonstration of the impact of area wide mass trapping of Red Palm weevil and Rhinoceros Beetle using aggregation pheromone lures in coconut plantations. In a book with title "In a Nutshell - Essays on Coconut", Coconut Development Board, Government of India. p.137-177.

Kalidas, P. 2004. Efficacy of aggregation pheromone in the management of rhinoceros beetle in oil palm in Andhra Pradesh. In Proceeding of National Seminar on Trends in Pheromone Research and Technology. National Research Centre for Groundnut, Junagadh, p.72-80.

Murali Mohan, K., Ramkumar and Srinivasa, Y. B. 2007. On natural parasitization and biological control: Case of the coconut caterpillar.

Norman, K., Basri, M. W., Zaidi, M. I. and Maimon, A. 1999. Population studies of 
Oryctes rhinoceros in an oil palm replant using pheromone traps. In Proceeding of the 1999 PORIM International Palm Oil Congress - Emerging Technologies and Opportunities in the next millennium. Palm Oil Research Institute of Malaysia, Kuala Lumpur, p.441-455.

Ochlschlager, A. C., Chinchilla, C. M., Gonzales, I. M., Jiron, L. F., Mexzon, R. and Morgan, B. 1993. Development of pheromone-based trapping system for Rhynchophorus palmarum (L.) (Coleoptera: Curculionidae) in oil palm. Environmental Entomology, 24: 10051012.

Rajalakshmi, L., Bharathiraja, A., Sakthivel, P. and Neelanarayanan, P. 2007. Utilization of aggregation pheromone for monitoring of rhinoceros beetle (Oryctes rhinoceros) in coconut palms (Cocos nucifera) and oil palm (Elaeis guineeesnsis) Groves. In Proceeding of National Seminar on Emerging Scenario in Zoology, Department of Zoology, National College, Tiruchirapalli, p.27-29.

Srinivasa Murthy et al., 1995 Proceeding of National Workshop on use of pheromones in IPM, DRR, Hyderabad

Vidhyasagar, P. S. P.V., Al-Saihati, A. A., A.Mohanna, O. E., Subbei, A. I. and Abdul Mohsin, A. M. 2000. Management of Red Palm Weevil Rhynchophorus ferrugineus Olivier, a serious pest of date palm in AlQatif, Kingdom of Saudi Arabia, Journal of Plantation Crops, 28: 35-43. 